\title{
Indian spinal injuries centre
}

\author{
A S Chahal AVSM VSM MS FRACS
}

Director, Indian Spinal Injury Centre, Pocket C, Vasant Kunj, New Delhi-110 037, India.

\begin{abstract}
A 110-bedded spinal injury centre is under construction in New Delhi. This centre will be equipped through Indo-Italian friendship with the latest medical and technical equipment. The centre will be ready in September 1992 for the treatment of acute injuries from Delhi and surrounding areas and will treat complicated cases referred by other centres/hospitals in India. Research and training of doctors, nurses and rehabilitation staff will be an integral part of the centre.
\end{abstract}

Key words: Indian spinal injuries centre; treatment; research and training; architectural plans.

\section{Introduction}

Care of acute spinal cord injuries and their rehabilitation is still a neglected area of medicine in India.

Incidence of spinal cord injuries is 15 per million. There are 12000 fresh traumatic paraplegics and tetraplegics every year. They have received scant attention from authorities and the medical fraternity due to poor prognosis and likely prolonged stay in hospital. Eighty per cent in India cannot afford proper treatment in a private hospital or specialised centre. In the last decade it has been appreciated that it is time the country developed some centre of excellence to provide good medical care and rehabilitation for this group.

\section{Historical background}

The armed forces in India were the first to realise the importance of establishing a modern paraplegic centre following the India-Pakistan conflicts of 1962 and 1965. In 1971 a 80-bedded spinal cord injury centre was established at The Military Hospital, Kirkee, Pune. This was very fortuitous because when the India-Pakistan conflict arose in December 1971 the centre had 46 fresh cases in 30 days, due to war. At the same time the first civilian paraplegic centre was established by Dr Mary Verghese in The Christian Medical College, Vellore South India, in 1968. A few centres of 10 or
20 beds were set up in the 1970s. In the 1980s the Indian Government realised that there was a need for a national centre to treat acute patients, as trauma has been on the increase. This centre will also be responsible for training doctors, nurses and paramedical staff for other centres in the country.

The Indian spinal injury centre (ISIC) of 110 beds made good progress, under the patronage of the late prime minister Rajiv Gandhi. In April 1989 the foundation stone was laid by the prime minister in 12 acres of open land on the outskirts of Delhi, $7 \mathrm{~km}$ from the airport. The building of the centre will be completed by June 1992. Modern medical equipment is coming from abroad under the Indo-Italian friendship programme. It is proposed to admit inpatients from July 1992.

The architectural plans of the centre are as follows. The basement will house services such as standby generators, air conditioning, water treatment plant, laundry, central sterilisation, medical and general stores, and the morgue (Fig 1).

On the ground floor there will be maximum patient activities, concentrated here to make them easily accessible to paraplegics in wheelchairs, and to trolleys. The various departments on the ground floor will be:

1 A diagnostic centre containing reception; outpatient services with radiology 


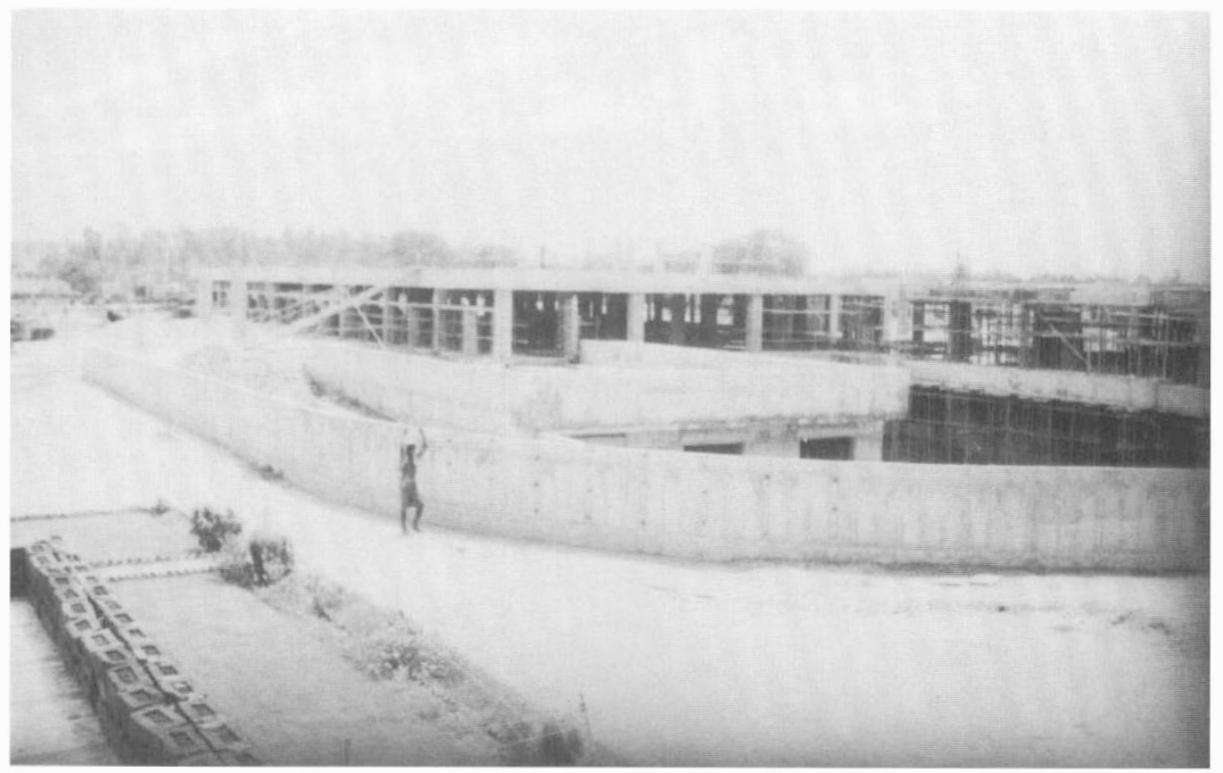

Figure 1 Building under construction. Basement and ground floor (1 September 91).

and a laboratory for routine haematology; a urodynamic laboratory; and a neurophysiology laboratory (Fig 2).

2 An emergency department with trauma and resuscitation room, operation room and 24-hour casualty service for spinal injuries and associated trauma (Fig 3).

3 A 6-bedded intensive care unit with monitors, respirators and other critical care facilities adjoining the emergency area.

4 A rehabilitation department with physiotherapy, occupational therapy and a gymnasium, planned with easy access to outpatient and inpatient departments.

5 Ward A, with 4 units of 6 beds, each with round the clock nursing facilities; and Ward B, a 30-bedded special ward comprising single, double and 4-bedded units, where patients can learn independent living under the supervision of ward staff (Fig 4).

The first floor has been planned to accommodate research. There will be a library and conference room besides an operating theatre and laboratories. In phase II, wards of 24 beds and 30 beds will be constructed above the wards on the ground floor. Lifts are being provided for easy access to this floor, along with a ramp where wheelchairs can climb up a gentle slope.

It is proposed to admit all acute spinal cord injuries from Delhi Union territory (9 million population) and from within a radius of 100 miles round Delhi (11 million population). With the incidence of 15 traumatic paraplegics per million (Delhi has the highest ratio in India of vehicles to people) we expect 300 fresh cases every year, with another 300 old cases needing admission to this centre.

To reduce the pressure, it is planned to build a half-way home, a residential complex with rehabilitation programmes and a sheltered workshop. Experience gained from such a community programme in a 100-bedded paraplegic home for soldiers, successfully run since 1974 under the guidance of the author, is being used as a guide.

A network of subcentres in other parts of the country will be established and their staff will be trained by ISIC Delhi, under a Ministry of Social Welfare networking plan. A research and training programme with the National Institute of Disability and Rehabi- 


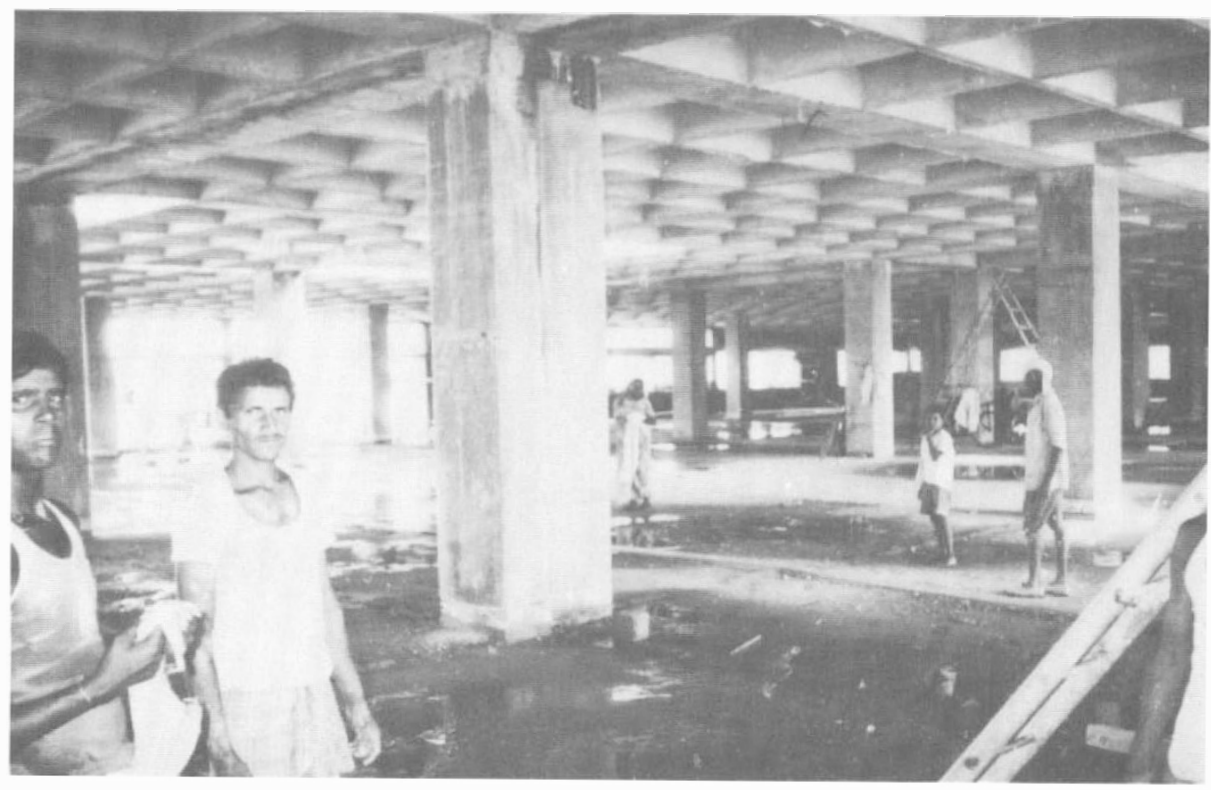

Figure 2 Diagnostic centre building on ground floor. Passage to basement between two walls.

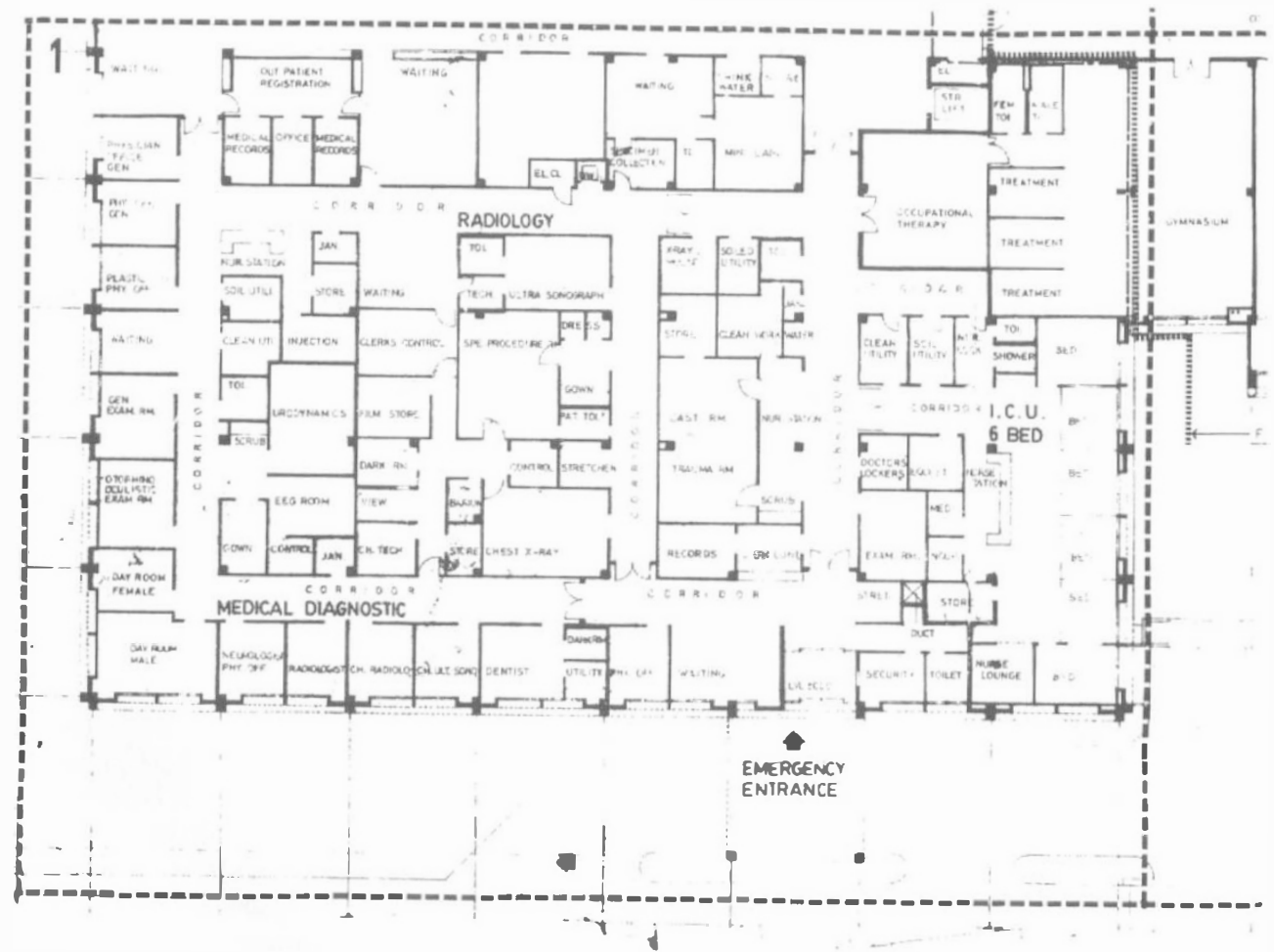

Figure 3 Architectural plans for diagnostic centre and emergency department on ground floor. 


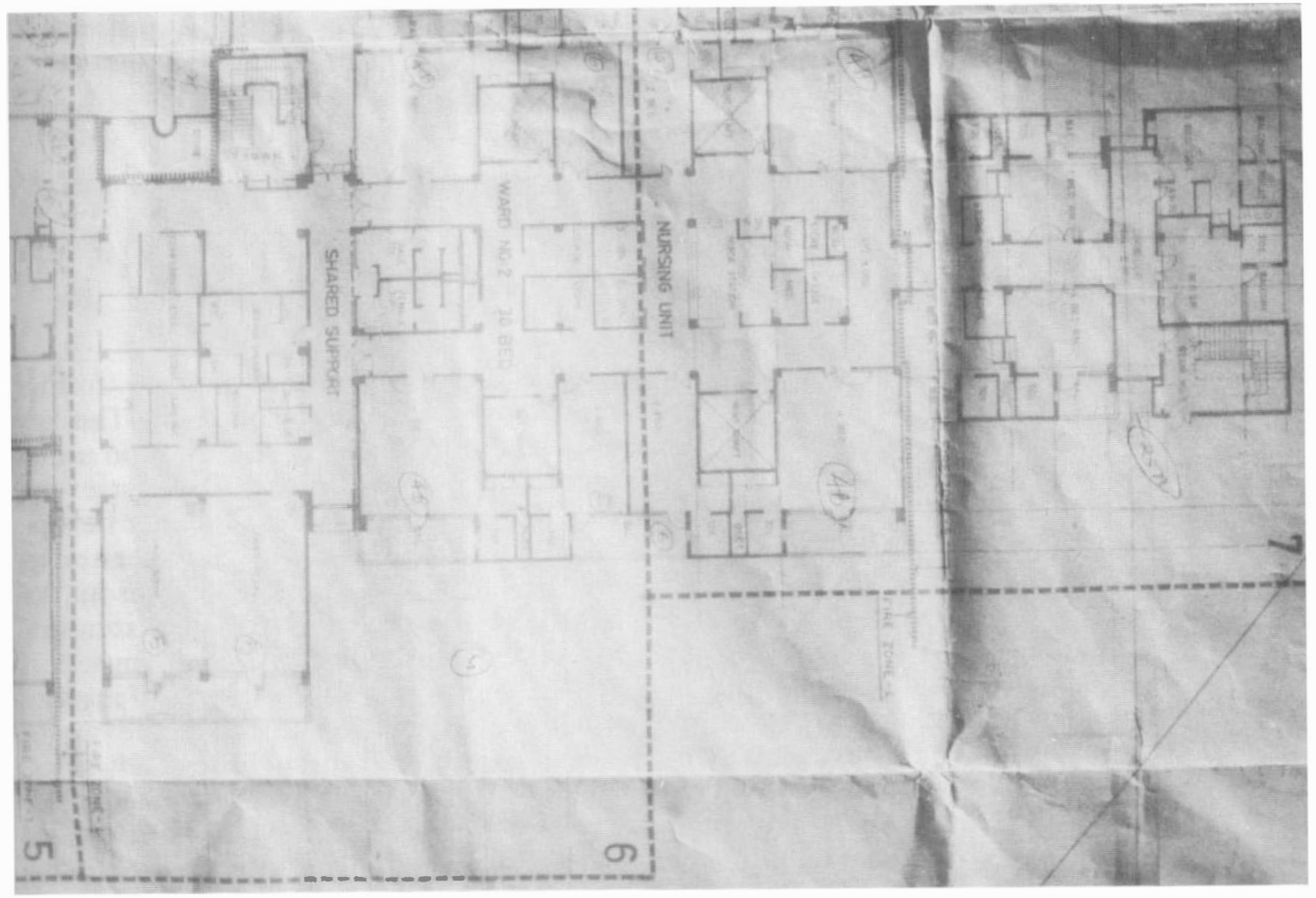

Figure 4 Plans of the ward on ground floor.

litation Research, USA is also being planned by the Ministry of Social Welfare.

This centre will, in a year or so, be ideal for holding workshops/training for South East Asia in collaboration with neighbouring countries. The International Society of Paraplegia has been requested to hold its annual scientific meeting in October 1995 in Delhi. This will promote the establishment of similar centres in India and neighbouring countries such as Nepal, Bangladesh, Burma, Thailand, Malaysia and Srilanka. Doctors, nurses and medical personnel trained in this centre will thus fill a void in the management and rehabilitation of traumatic paraplegia in South East Asia. The last regional international conference of ISIC, held in Delhi in February 1985, generated a great deal of interest in setting up spinal injury services. The result was that the Ministry of Social Welfare took it up as a special rehabilitation project. The centre will soon be ready to play its role as a national institute for treatment and rehabilitation of paraplegics. 